\title{
The Impact of Leadership on Innovation in Organizations
}

\author{
Tănase Mihaela \\ Dr., Alexandru Ioan Cuza" University, Iaşi, Romania
}

\begin{abstract}
Innovation has become a benchmark for development and performance in organizations around the world. Leadership style seems to influence innovation in many activity sectors. Several studies have shown that leadership positively influences organizational innovation (Jung et al., 2003). However, the contextual conditions under which this effect occurs or is highlighted hasn't been researched thoroughly.

Despite the growing interest in the development of innovative technologies, many elements remain unknown about how to best facilitate the innovation process. Through a review of innovation and leadership literature, it would seem that leaders are one of the main driving forces in increasing innovative production.

In this paper, it was examined if there is a relationship between the transformational leadership style, the percentage of innovation spending, and the number of new and improved services that provide insight into the success of innovation in companies operating in the service sector. This paper supplements the literature on transformational leadership and innovation from the analysis performed in previous studies.
\end{abstract}

Keywords: leadership, innovation, organizations, transformational leadership

\section{Introduction}

There is a ubiquitous number of studies that have shown that leadership positively influences organizational innovation (Jung et al., 2003). However, this subject has not been properly examined in the contextual conditions in which this effect occurs or is highlighted, nor analyzed at the level of organizations in the service sector in the N-E region of Romania.

In this article the following two objectives were considered: bring additional value to transformational leadership and innovation literature starting from the analysis of existing research and presenting the components of transformational leadership that facilitate innovation. Through this study we examined whether there is a relationship between transformational leadership style and innovation variables based on the following findings: transformational leadership style focuses on motivating subordinates for the good of the group, organization and society (Bass, 1999) and innovation variables included the percentage of spending allocated to innovation and the number of new and improved services that offer a perspective on the success of innovation in service sector organizations.

\section{Transformational leadership and innovation}

Through the transformational leadership style, the behavior of leaders is usually described as a driving force of innovation for the following three reasons (García-Morales et al., 2012): first, the component of transformational leadership ,individualized consideration” 
will act as a reward for subordinates by recognizing and motivating them. Second, another component of transformational leadership, ,intellectual stimulation”, will enhance the exploratory thinking of subordinates by supporting innovation, autonomy, and challenge. The third component, ,inspirational motivation" will stimulate the subordinates' process of generating ideas by encouraging them to work in line with the organization's vision. Moreover, Bass (1990) explains that transformational leaders contribute to the work efficiency of subordinates and this has a positive impact on their creativity. This is because subordinates develop their creativity through feelings of self-efficacy (Lee et al., 2010; García-Morales et al., 2012).

Transformational leaders use another method to enoucrage the crativity of subordinates, namely emotional relationships. According to Bass (1990), one of the main characteristics of transformational leaders is that they build emotional relationships with their subordinates. These relationships, as Hunt et al. (2004), contribute to the increase of creativity and implicitly of innovation.

The concept of „transformational leadership” encompasses four sub-dimensions: Idealized influence, in which leaders are admired and respected; Inspirational motivation, which reflects how leaders motivate and inspire employees by providing meaning and challenge in their work; Intellectual stimulation, which refers to stimulating employees' efforts to be innovative and creative by questioning hypotheses, reframing problems, and approaching old situations in new ways; and Individualized consideration, which focuses on leaders who pay more attention to the needs of each follower to achieve and grow, acting as a coach or mentor (Bass and Riggio, 2006). Previous studies have consistently suggested that transformational leadership is related to the positive attitudes and performances of subordinates (Perko et al., 2014).

Research in the field of transformational leadership reveals the significance of this type of leadership at the individual and organizational levels (Wang \& Howell, 2010). Transformational leadership focuses on creating transformational skills by increasing motivation, employee involvement, and empowering them to meet organizational goals (Yulk, 2010).

Transformational leaders could enhance the exploration of innovation by applying individualized consideration and inspirational motivation. Thus, if to employees are given the understanding, support, and encouragement of the transformational leader, they are more likely to respond to such leader's change initiatives even in the face of a turbulent environment. When leaders demonstrate idealized influence and inspirational motivation, employees can work harder to achieve organizational goals and objectives because they view such leaders as role models.

Innovation also depends on organizational culture, more precisely, the degree of organizational support. Mann (2005) argued that organizational support can be divided into three forms: 1) organizational encouragement of innovation, i.e. the degree to which researchers feel and perceive various types of support (supporting ideas, trust, emotional security and acceptance); 2) access to the necessary resources, i.e. first of all time, materials, expertise and information; 3) empowerment, i.e. the extent to which researchers feel encouraged and experience the freedom to approach a task, the degree of autonomy. The presence of these values and resources can lead to the effective improvement of innovation performance (Bain et al., 2001). In particular, the autonomy or freedom granted to pursue unique ideas is related to the performance of innovation (Hunter et al., 2007). 


\section{The relationship between transformational leadership and innovation}

Innovation is important worldwide, and leadership style seems to influence innovation in different industries (Amar and al., 2009). Canon and Nokia are two companies that have benefited from innovation. These companies maintained their global market share by developing new and improved products (Bowonder and al.,2010). The benefits of innovation, such as software innovation, are not without risks, because the failure of software innovation can cost shareholders and taxpayers billions of dollars each year (Charette, 2005). Even with the high-risk and high cost of software innovation, for example, internet and software companies dedicates $13 \%$ to research and development, (Jaruzelski and Dehoff, 2008). Previous research has indicated that leadership styles can affect the output and success of innovation: (Matzler and al.,2008). Boerner and al., (2007) investigated the relationship between transformational leadership style, innovation, performance, and organizational behavior; Matzler et al. (2008) investigated the relationship between transformational style and innovation in small and medium-sized enterprises (SMEs).

Business innovation not only involves the development of new conventional products and services, but also the development of new knowledge to achieve new business models and rules (Nonaka et al., 2014). In this sense, the creation of knowledge through innovative leadership to achieve new business innovations is of particular importance (Von Krogh et al., 2012).

Managers and subordinates must constantly ask themselves how to create, use and share knowledge in their practical activities and consider what kind of strategic approaches are needed to create knowledge in order to implement busienss invoation as a general corporate activity. In other words, it is important to focus on methods (mechanisms or processes) for creating strategic knowledge. Therefore, the most pressing management issue is what kind of leadership practitioners should acquire and implement in order to continuously create valuable high-quality knowledge both inside and outside their companies and strategically bring new innovations.

The aim of the research is to determine the relationship between transformational leadership and innovation in organizations, through the number of new or significantly improved services placed on the market and the percentage of revenues related to innovation.

\section{Research hypotheses}

RQ: Transformational leadership has a direct impact on organizational innovation.

According to Vaccaro et al., (2008), transformational leadership stimulates employees to generate and implement innovations. Transformational leaders benefit from inspirational motivation and intellectual stimulation, which are critical factors for innovation (Zuraik and Kelly 2019). Jung's research (Jung et al., 2003) shows that transformational leadership is significantly and positively linked to organizational innovation. In addition, its impact on the organization's readiness to innovate and on the success of innovations in the market was confirmed.

RQ1: Is there a relationship between the transformational leadership style measured by Multifactor Leadership Questionnaire (MLQ) and the number of new or significantly improved services introduced to the market? 
H1: There is no statistically significant relationship between the transformational leadership style measured by MLQ and the number of new and significantly improved services introduced to the market.

$\mathrm{H} 2$ : There is a statistically significant relationship between the transformational leadership style measured by MLQ and the number of new or significantly improved services introduced to the market.

Innovation is important worldwide, and leadership style seems to influence innovation in different industries (Amar, Hentrich and Hlupic, 2009).

Nemanich et Keller (2007) revealed a positive correlation between transformational leadership and new or improved products. Two of the main traits of transformational leadersneed for openness and flexibility - can be reason for the effectiveness of transformational leadership in new product innovation. These findings support the need for organizations leaders to adopt leadership styles within their innovation goals to increase the likelihood of optimal success.

Matzler et al. (2008) indicated that there are research opportunities related to understanding the relationships between leadership styles and innovation for different sectors of activity. Given the high-cost of failures and the high percentage of innovation spending within organizations (eg software companies, Jaruzelski and Dehoff, 2008), researching the relationship between leadership and innovation could provide great benefits to any particular industry.

RQ2: Is there a relationship between the transformational leadership style measured by MLQ and the percentage of revenue related to innovation?

H3: There is no statistically significant relationship between the transformational leadership style measured by MLQ and the percentage of revenue related to innovation.

H4: There is a statistically significant relationship between the transformational leadership style measured by MLQ and the percentage of revenue related to innovation.

\section{How to measure transformational leadership}

The components of transformational leadership are measured through the Multifactorial Leadership Questionnaire (Bass and Avolio, 2000). It contains twenty items, built on a 5-step Likert scale, which are distributed in equal numbers on each component. The exception is the idealized influence to which 8 items were assigned instead of 4; they are divided equally into the two categories, namely: idealized attributes and idealized behaviors. Tractional leadership is measured through a number of 12 MLQ items developed by Bernard M. Bass of New York University and Bruce J. Avolio of Michael G. Foster University School of Business, USA, in 1985 and perfected over time.

The MLQ questionnaire (MLQ-known as MLQ 5X short or standard MLQ) measures a wide range of leadership styles, from passive leaders, to leaders who give contingent rewards to subordinates, to leaders who turn their subordinates into leaders. It identifies the characteristics of a transformational leader and helps respondents to discover how they perceive themselves as well how the people they work with perceive them. Success can be measured by a retesting program to track changes in leadership style. The MLQ features are listed below: 
- measures, explains and demonstrates to people the key factors that differentiate truly exceptional leaders from the least exceptional;

- assesses the effectiveness of both individual and team leadership capacity and provides data that defines strengths and development opportunities;

- differentiates efficient from inefficient leaders at all organizational levels;

- evaluates the effectiveness of an organization's leadership;

- valid between different cultures and different types of organizations.

The Multifactorial Leadership Questionnaire also has the following advantages: it is easy to follow, requires 15 minutes to complete; MLQ provides an excellent relationship between survey data and organizational outcome; MLQ is the benchmark for transformational leadership.

\section{Conclusions}

In conclusion, through this report it was summarized the theoretical implications of the impact of transformational leadership on previously researched variables on innovation.

The proposed objectives were achieved, namely: brought additional value to existing literature on transformational leadership. Additionally, the components of transformational leadership that facilitate innovation were presented in detail and were refined and supported by the conceptual theoretical model which highlights the influence of transformational leadership on innovation in organizations.

The new variables introduced in the research hypotheses capture the number of new or significantly improved services introduced on the market and the percentage of revenues dependent on innovation.

\section{References}

Amar, A. D., Hentrich, C., Hlupic, V. (2009). To be a better leader, give up authority. Harvard Business Review, 87(12), 22-24.

Bain, P. G., Mann, L. and Pirola-Merlo, A. (2001). 'The Innovation imperative: The relationships between team climate, innovation, and performance in research and development teams', Small Group Research, Vol. 32, No. 1, pp. 55-73.

Bass, B. M. (1990). From transactional to transformational leadership: Learning to share the vision. Organizational Dynamics, (Winter): 19-31.

Bass, B.M. (1999), "Two decades of research and development in transformational leadership", European Journal of Work and Organizational Psychology, Vol. 8 No. 1, pp. 9-32.

Bass, B. M. \& Avolio, B. J. (2000). MLQ Multifactor Leadership Questionnaire Redwood City: Mind Garden.

Bass, B. M., \& Riggio, R. E. (2006). Transformational Leadership (2nd ed.). New Jersey, London: Lawrence Erlbaum Associates. 
Bowonder, B., Dambal, A., Kumar, S., \& Shirodkar, A. (2010). Innovation strategies for creating competitive advantage. Research Technology Management, 53(3), 19-32.

García-Morales, V. J., Jiménez-Barrionuevo, M. M. and Gutiérrez-Gutiérrez, L. (2012), Transformational leadership influence on organizational performance through organizational learning and innovation, Journal of Business Research, Vol. 65 No. 7, pp. 1040-1050.

Hunt, J. G., Stelluto, G. E., \& Hooijberg, R. (2004). Toward new-wave organization creativity: Beyond romance and analogy in the relationship between orchestra-conductor leadership and musician creativity. Leadership Quarterly, 15, 145-162.

Hunter, S. T., Bedell, K. E., Mumford, M. D. (2007). Climate for creativity: A quantitative review. Creativity Research Journal, 19, 69-90.

Jung DI, Chow C, Wu A (2003). The role of transformational leadership in enhancing organizational innovation: Hypotheses and some preliminary findings. Leadersh. Q. 14: 525544.

Lee, P., Gillespie, N., Mann, L., and Wearing, A. (2010) Leadership and Trust: Their Effect on Knowledge Sharing and Team Performance. Management learning, 41(4), p 473-49.

Matzler, K., Schwarz, E. , Deutinger, N. , \& Harms, R. (2008). The relationship between transformational leadership, product innovation and performance in SMEs. Journal of Small Business and Entrepreneurship, 21(2), 139-151.

Nemanich, L. A., \& Keller, R. T. (2007). Transformational leadership in an acquisition: A field study of employees. The Leadership Quarterly, 18(1), 49-68.

Nonaka, I., Kodama,M., Hirose, F. Kohlbacher, Dynamic fractal organizations for promoting knowledge-based transformation-A new paradigm for organizational theory. European Management Journal, 32 (1) (2014), pp. 137-146.

Perko, K., Kinnunen, U., \& Feldt, T. (2014). Transformational leadership and depressive symptoms among employees: Mediating factors. Leadership \& Organization Development Journal, 35(4), 286-304.

Vaccaro, A., Madsen, P., \& Horta, H. (2008). Transparency andinformation and communication technologies: Social responsibil-ity and accountability in business and education. Charlottesville,VA: Philosophy Documentation Center.

Von Krogh, G., Nonaka I., Rechsteiner, L., 2012. Leadership in organizational knowledge creation: A review and framework. Journal of Management Studies 49, 240-277.

Wang, X.H. and Howell, J.M. (2010) Exploring the Dual-Level Effects of Transformational Leadership on Followers. Journal of Applied Psychology, 95, 1134-1144.

Yukl, G. (2010). Leadership in organizations. Upper Saddle River, NJ: Prentice Hall.

Zuraik, A. and Kelly, L. (2019), The role of CEO transformational leadership and innovation climate in exploration and exploitation, European Journal of Innovation Management, Vol. 22 No. 1, pp. 84-104. 


\section{Acknowledgements}

This work was cofinanced from the European Social Fund through Operational Programme Human Capital 2014-2020, project number POCU/380/6/13/125015" Development of entrepreneurial skills for doctoral students and postdoctoral researchers in the field of economic sciences" 